\title{
Applied anatomy and clinical significance of the maxillofacial and mandibular regions of the barking deer (Muntiacus muntjak) and sambar deer (Rusa unicolor)
}

\author{
K. Keneisenuo ${ }^{1}$, O.P. Choudhary ${ }^{1}$,, P. Priyanka ${ }^{2}{ }^{\circledR}$, P.C. Kalita ${ }^{1}$, A. Kalita ${ }^{1}$, P.J. Doley ${ }^{1}$, \\ J.K. Chaudhary ${ }^{3}$ \\ ${ }^{1}$ Department of Veterinary Anatomy and Histology, College of Veterinary Sciences and Animal Husbandry, \\ Central Agricultural University (I), Selesih, Aizawl, Mizoram, India \\ ${ }^{2}$ Department of Veterinary Microbiology, College of Veterinary Sciences and Animal Husbandry, \\ Central Agricultural University (I), Jalukie, Peren, Nagaland, India \\ ${ }^{3}$ Department of Animal Genetics and Breeding, College of Veterinary Sciences and Animal Husbandry, \\ Central Agricultural University (I), Selesih, Aizawl, Mizoram, India
}

[Received: 15 January 2020; Accepted: 20 February 2020]

Background: There is no previously reported information on the applied anatomy and clinical significance of the maxillofacial and mandibular regions of the barking deer and sambar deer.

Materials and methods: Therefore, the present study was designed to provide some important clinical landmarks related to tracking of the infraorbital, mental and mandibular nerves with its clinical implications in regional anaesthesia in both the species. Results: In the present study, the distance between the most lateral bulging of the facial tuberosity to the infraorbital foramen and from the latter to the root of the alveolar tooth directly ventral to it was found to be $2.65 \pm 0.01 \mathrm{~cm}$ and $0.90 \pm$ $\pm 0.02 \mathrm{~cm}$ in males; $2.75 \pm 0.01 \mathrm{~cm}, 1.11 \pm 0.01 \mathrm{~cm}$ in females of barking deer and $4.57 \pm 0.01 \mathrm{~cm}$ and $1.83 \pm 0.02 \mathrm{~cm}$ in males; $4.52 \pm 0.02 \mathrm{~cm}$ and $1.76 \pm 0.02 \mathrm{~cm}$ in females of sambar deer. The infraorbital foramen was small, elliptical and was located at the level of first superior premolar teeth in barking deer and sambar deer. The facial tuberosity was located above the third superior premolar teeth in the barking deer but was located at the level of the first superior molar teeth in sambar deer. The distance between the lateral alveolar root of the third inferior incisor tooth to the mental foramen was $2.84 \pm 0.01 \mathrm{~cm}$ in males, $2.78 \pm 0.01 \mathrm{~cm}$ in females of barking deer and $3.04 \pm 0.02 \mathrm{~cm}$ in males, $2.96 \pm 0.01 \mathrm{~cm}$ in females of sambar deer which is an important landmark for achieving the location of the mental foramen nerve for the regional nerve block in both the species. The mandible of both the species showed oval-shaped mental foramen with unossified mandibular symphysis. Conclusions: The present study revealed that most of the parameters showed a statistically significant difference between the sexes in barking deer and sambar deer; however, from the practical point of view, these differences were meager. The results were discussed with regard to their clinical applications in various regional anaesthesia performed in maxillofacial and mandibular regions of both the species. (Folia Morphol 2021; 80, 1: 170-176)

Key words: barking deer, sambar deer, infraorbital, mental, mandibular, nerve, regional anaesthesia 


\section{INTRODUCTION}

The barking deer (Muntiacus muntjak) is a cervid species deer native to South and Southeast Asia that has been listed as 'least concern' on the International Union for the Conservation of Nature (IUCN) red list [32]. They are relatively small tropical deer that have a solitary lifestyle [21] and wide natural distribution, ranging throughout the large parts of South-east Asia [24]. The males have short antlers protruding from long body hair-covered pedicles above the eyes, while females have small bony knobs. Males have preorbital glands which are larger than in females [2] and they use these glands to mark the ground [1, 3].

The sambar deer (Rusa unicolor) is a large deer of cervid species native to the Indian subcontinent, Southern China and Southeast Asia, that has been listed as 'vulnerable' by the IUCN red list since 2008 due to decrease in their population year by year $[20,33]$. The males have rugged antlers having simple brow tines along with forked beams at its tip and are dropped annually. The barking and sambar deer are protected under Schedule III of the Indian Wildlife Protection Act, 1972.

The regional anatomy is the important branch of anatomy that deals with the form and relationships of various anatomic structures present in a specific area. It is one of the major foundations of clinical and surgical practice as it enables the clinician/surgeon to visualise the details of the structures relevant to the case at hand [12]. The knowledge of the regional anatomy of the head is crucial due to the presence of the vital organs and structures such as the brain, tongue, eye, ears, nose, lips, horn and skull. Due to the presence of these structures, the function of the head is to coordinate the body, deglutition, olfaction and defence [12]. Numerous investigations have been done on the regional anatomy of the head region of the domestic and wild animals including ox, horse, sheep, goat, dog, pig and camel [4-6, 12, 15, 26, 28].

The relationship and forms of all organs that are located in a particular area are directly concerned with regional anatomy helping the clinician as well as surgeon to visualise details of the structures relevant to the case at hand and form one of the important foundations for clinical and surgical practice [12]. It has been reported previously that the infraorbital nerve and mental nerve pass from the infraorbital foramen and mental foramen, respectively [13, 14]. In an emergency situation that requires surgical intervention, it is very easy to locate this region as a topographical landmark for quick and easy anaesthesia to block the infraorbital and mental nerve. Knowing the topographic and morphometric anatomy of the infraorbital and mental foramen provides simplicity in veterinary surgery during an emergency $[12,27]$.

There is no previously reported information on the applied anatomy and clinical significance of the maxillofacial and mandibular region of barking deer and sambar deer. Therefore, the present study has been carried out to provide information on some clinically important parameters and landmarks on the maxillofacial and mandibular region in both the species. Thus, the results shown in this study will aid the clinicians in the implication of regional anaesthesia in the maxillofacial and mandibular regions in both the species.

\section{MATERIALS AND METHODS}

The study was conducted on the maxillofacial and mandibular regions of eight adult barking deer and sambar deer of either sex. The skull samples were collected from the Aizawl Zoological park, Aizawl, Mizoram after taking official permission from the Principal Chief Conservator of Forest and Chief Wildlife Warden, Government of Mizoram, Aizawl vide letter no. A. 33011/5/2017-CWLW/91 dated 15.03.2019. After collection, the samples were processed by the hot water maceration technique. The present study was carried out in the Department of Veterinary Anatomy and Histology, College of Veterinary Sciences and Animal Husbandry, Selesih, Aizawl, Mizoram and Interpretation Centre, Aizawl Zoological Park, Aizawl, Mizoram. The radiograph of the mandible was carried out by the Siemens X-Ray machine (500 mA) at Diagnostic Division Radiology and Imaging, Mizoram Health Care, Aizawl, Mizoram.

Altogether a total of eleven measurements were taken in the upper jaw and mandibles of both the species by using digital vernier calliper (Resolution $0.01 \mathrm{~mm}$ or 0.0005 inches: Accuracy $\pm 0.03 \mathrm{~mm}$ ) and the results were expressed as mean \pm standard deviation (SD). The parameters taken in maxillofacial and mandibular regions are delineated below and revealed in Figures 1-3.

A. Facial tuberosity to the infraorbital foramen: It was measured from the level of most lateral bulging of facial tuberosity to mid-level of the infraorbital foramen.

B. Infraorbital foramen to root of alveolar tooth: It was measured from the mid-level of the infraorbital foramen to the alveolar root of the superior first premolar tooth. 


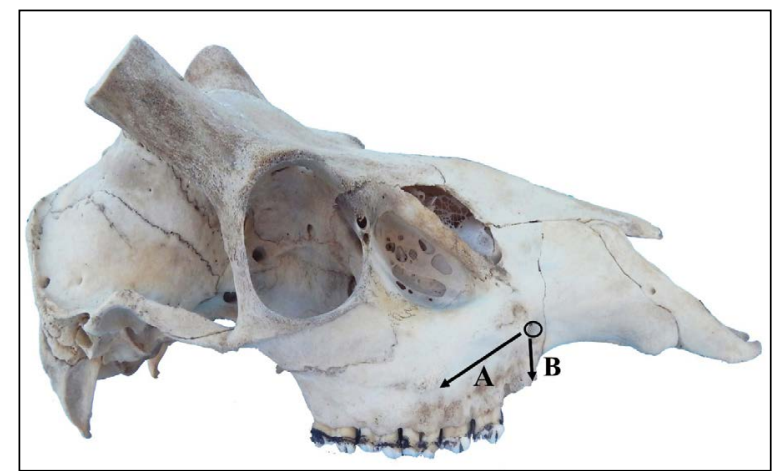

Figure 1. Lateral view of the skull of sambar deer showing facial tuberosity to infraorbital foramen (A) and infraorbital foramen to root of the superior first premolar tooth (B).

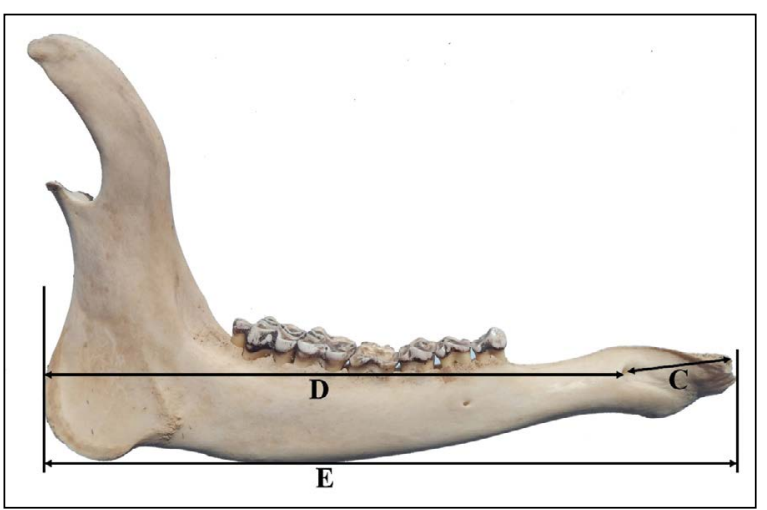

Figure 2. Lateral view of the mandible of sambar deer showing measurements; lateral alveolar root of inferior third incisor tooth to mental foramen $(C)$, mental foramen to the caudal mandibular border (D) and mandibular length (E).

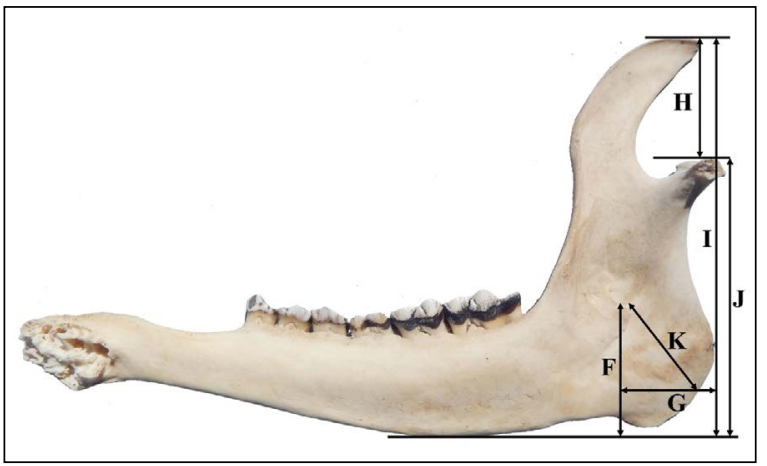

Figure 3. Medial view of mandible of sambar deer showing measurements; mandibular foramen to the horizontal plane at the level of the ventral margin of the mandible $(F)$, below mandibular foramen to caudal mandibular border (G), maximum height of mandible to the condylar process $(\mathrm{H})$, maximum mandibular height (I), condylar process to the ventral margin of the mandible $(\mathrm{J})$ and mandibular foramen to the border of mandibular angle $(\mathrm{K})$.
C. Lateral alveolar root to mental foramen: It was measured from the lateral extent of the alveolar root of the third inferior incisor tooth to the mental foramen.

D. Mental foramen to the caudal mandibular border: It was measured from the level of the mental foramen to caudal border of the ramus of the mandible.

E. Mandibular length: It was measured from the level of the rostral extremity of the alveolar root of the central inferior incisor tooth to the transversal plane at the level of the caudal border of the mandible.

F. Mandibular foramen to the horizontal plane at the level of the ventral margin of the mandible: It was measured from the ventral limit of the mandibular foramen to the horizontal plane at the level of the ventral margin of the mandible.

G. Caudal border of the mandible to below mandibular foramen: It was measured from the caudal most border of the mandible to the vertical line produced by a description of measurement of mandibular foramen to the ventral margin of the mandible.

H. Condylar process to the height of mandible: It was measured from the condylar process to the maximum height of the mandible.

I. Maximum mandibular height: It was measured from the highest level of the coronoid process perpendicularly to the ventral mandibular margin of the mandible.

J. Condylar process to the ventral margin of the mandible.

K. Mandibular angle to mandibular foramen: It was measured from the extreme caudal border of angle of the mandible to mandibular foramen.

\section{Statistical analysis}

All the above parameters of the maxillofacial and mandibular regions of barking deer and sambar deer were obtained. All the measurements obtained were analysed by routine statistical analysis [30] and Student " $\mathrm{t}$ " test by the Statistical Package for the Social Sciences (IBM, SPSS, 20.0 version) programme.

\section{RESULTS}

The infraorbital foramen, mandibular foramen and mental foramen on the medial and lateral surface of the maxillofacial and mandibular regions are shown 


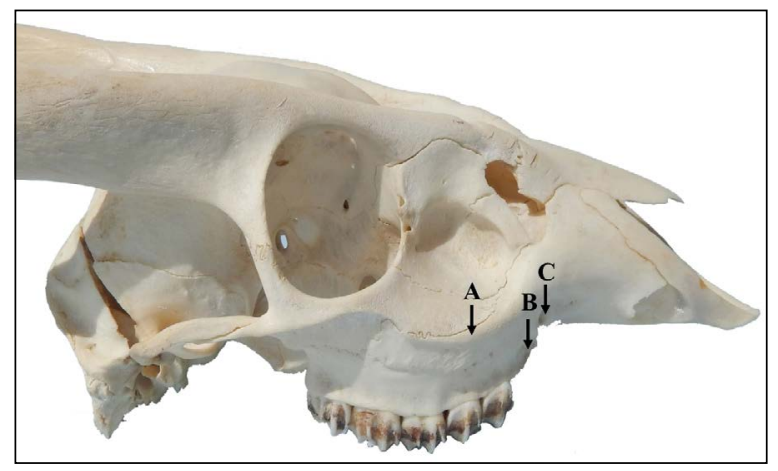

Figure 4. Lateral view of the skull of barking deer showing facial tuberosity $(A)$; root of the superior first premolar tooth $(B)$ and infraorbital foramen (C).

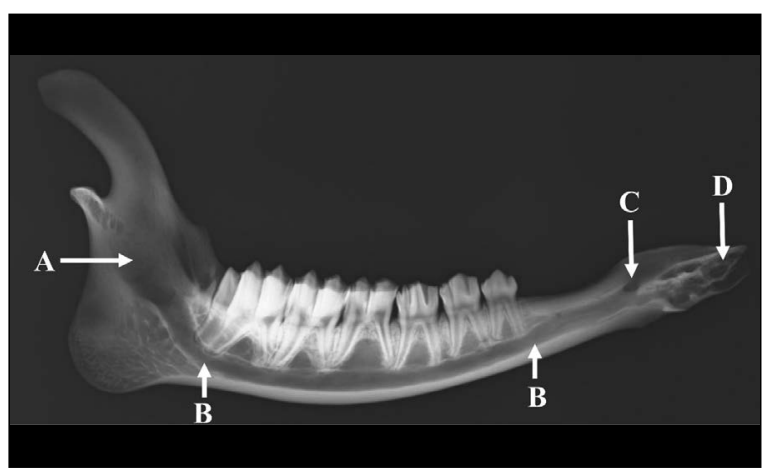

Figure 5. Mediolateral radiographical view of the mandible of barking deer showing mandibular foramen $(A)$, mandibular foramen $(B)$, mental foramen (C) and root of the lateral alveolar tooth (D).

Table 1. The measurements of the maxillofacial and mandibular region in barking deer and sambar deer in centimetres (mean \pm standard deviation)

\begin{tabular}{|c|c|c|c|c|c|c|}
\hline \multirow[t]{2}{*}{ Parameters\# } & \multicolumn{2}{|c|}{ Barking deer } & \multirow[t]{2}{*}{$\mathbf{P}$} & \multicolumn{2}{|c|}{ Sambar deer } & \multirow[t]{2}{*}{$\mathbf{P}$} \\
\hline & Male & Female & & Male & Female & \\
\hline A & $2.65 \pm 0.01$ & $2.75 \pm 0.01$ & $<0.01^{* *}$ & $4.57 \pm 0.01$ & $4.52 \pm 0.02$ & $<0.05^{*}$ \\
\hline B & $0.90 \pm 0.02$ & $1.11 \pm 0.01$ & $<0.01^{* *}$ & $1.83 \pm 0.02$ & $1.76 \pm 0.02$ & $<0.01^{* *}$ \\
\hline C & $2.84 \pm 0.01$ & $2.78 \pm 0.01$ & $<0.01^{* *}$ & $3.04 \pm 0.02$ & $2.96 \pm 0.01$ & $<0.01^{* *}$ \\
\hline$D$ & $12.87 \pm 0.01$ & $14.46 \pm 0.02$ & $<0.01^{* *}$ & $23.66 \pm 0.01$ & $23.59 \pm 0.01$ & $<0.01^{* *}$ \\
\hline$E$ & $15.77 \pm 0.01$ & $17.27 \pm 0.02$ & $<0.01^{* *}$ & $28.10 \pm 0.01$ & $27.96 \pm 0.01$ & $<0.01^{* *}$ \\
\hline $\mathrm{F}$ & $2.49 \pm 0.01$ & $2.39 \pm 0.02$ & $<0.01^{* *}$ & $5.17 \pm 0.01$ & $5.10 \pm 0.02$ & $<0.01^{* *}$ \\
\hline G & $2.15 \pm 0.01$ & $2.09 \pm 0.01$ & $<0.01^{* *}$ & $3.80 \pm 0.01$ & $3.71 \pm 0.01$ & $<0.01^{* *}$ \\
\hline $\mathrm{H}$ & $2.89 \pm 0.01$ & $2.79 \pm 0.01$ & $<0.01^{* *}$ & $5.29 \pm 0.01$ & $5.21 \pm 0.01$ & $<0.01^{* *}$ \\
\hline I & $7.88 \pm 0.01$ & $7.78 \pm 0.02$ & $<0.01^{* *}$ & $15.96 \pm 0.01$ & $15.78 \pm 0.02$ & $<0.01^{* *}$ \\
\hline J & $4.89 \pm 0.01$ & $4.39 \pm 0.01$ & $<0.01^{* *}$ & $10.60 \pm 0.01$ & $10.50 \pm 0.01$ & $<0.01^{* *}$ \\
\hline K & $2.49 \pm 0.03$ & $2.39 \pm 0.02$ & $<0.01^{* *}$ & $5.16 \pm 0.02$ & $5.11 \pm 0.01$ & $<0.01 * *$ \\
\hline
\end{tabular}

\#As mentioned in alphabetical order in materials and method. Level of significance at $5 \%$; ${ }^{*}$ Significant $(p<0.05)$; **Highly significant $(p<0.01)$.

in Figures 4, 5. The measurement points taken to determine the topographic and morphometric location of the mental foramen are shown in Figures 2, 3. In the present study, the infraorbital foramen was small, elliptical and was located at the level of first superior premolar tooth in barking deer and sambar deer (Figs. 1, 4). The alveolar border of mandible presented 6 alveoli for the 3 superior premolar and 3 superior molar teeth. The facial tuberosity was located dorsally to the third superior premolar tooth in barking deer but was at the first superior molar tooth in sambar deer. The preorbital fossa was wide and deep in both the species with upper canine teeth on the maxilla. The mandible of both the species showed oval mental foramen with unossified mandibular symphysis. The results of the measurements are listed in Table 1.
The present study revealed that all the obtained parameters differed statistically significantly $(p<0.01$ and $p<0.05$ ) between the males and females of barking deer and sambar deer respectively; however, from the practical point of view, these differences were meager.

\section{DISCUSSION}

In the present study, facial tuberosity of barking deer was located above the third superior premolar tooth which has also been reported in ox [13], chital [18] and blackbuck [9], while it was located at the level of first superior molar tooth in sambar deer. However, the facial tuberosity of the Madras Red sheep was prominent and placed at the level of $5^{\text {th }}$ cheek tooth (second superior molar tooth) [31]. The distance between the most lateral bulging of the 
facial tuberosity to the infraorbital foramen and from the latter to the root of the alveolar tooth directly ventral to it was $2.65 \pm 0.01 \mathrm{~cm}$ and $0.90 \pm 0.02 \mathrm{~cm}$ in males; $2.75 \pm 0.01 \mathrm{~cm}, 1.11 \pm 0.01 \mathrm{~cm}$ in females of barking deer and $4.57 \pm 0.01 \mathrm{~cm}$ and $1.83 \pm 0.02 \mathrm{~cm}$ in males; $4.52 \pm 0.02 \mathrm{~cm}$ and $1.76 \pm 0.02 \mathrm{~cm}$ in females of sambar deer (Table 1). However, the same parameter was reported as $1.6-1.8 \mathrm{~cm}$ and $1.3-1.6 \mathrm{~cm}$ in West African Dwarf goats [26]; $2.06 \pm 0.14 \mathrm{~cm}$ and $1.13 \pm 0.11 \mathrm{~cm}$ in Gwembe Valley dwarf goat [17]; $2.8 \mathrm{~cm}$ and $2.5 \mathrm{~cm}$ in Iranian native cattle [23]; $1.85 \pm 0.14 \mathrm{~cm}$ and $1.75 \pm 0.19 \mathrm{~cm}$ in black Bengal goat [34] and $2.37 \pm 0.00 \mathrm{~cm}$ and $0.72 \pm 0.00 \mathrm{~cm}$ in blackbuck [10]. The infraorbital nerve block can be achieved extraorally by injecting anaesthetic drugs approximately $1 \mathrm{~cm}$ in barking deer and $1.8 \mathrm{~cm}$ in sambar deer above the root of the first superior premolar tooth in the infraorbital foramen. The infraorbital nerve block is used in the surgical interventions related to the upper lip, nose and skin supplied by the infraorbital nerve.

The above-recorded parameters were of clinical importance because the facial tuberosity is remarkable even in live animals providing a clear guide for tracking the infraorbital nerve and its desensitisation during the manipulations in the skin of the upper lip, nostril and face at the level of the foramen. The infraorbital foramen was small, elliptical and located at the level of the first superior premolar tooth in barking deer and sambar deer which was also reported in chital [18] and blackbuck [9]. However, the same foramen was located dorsal to the second premolar in red Sokoto (Maradi) goats [25].

The distance between the lateral alveolar root of the third inferior incisor tooth to the mental foramen was $2.84 \pm 0.01 \mathrm{~cm}$ in males, $2.78 \pm 0.01 \mathrm{~cm}$ in females of barking deer and $3.04 \pm 0.02 \mathrm{~cm}$ in males, $2.96 \pm 0.01 \mathrm{~cm}$ in females of sambar deer (Fig. 2, Table 1) which is an important landmark for achieving the location of the mental foramen nerve for the regional nerve block in both the species, whereas it was $1.6 \pm 0.22 \mathrm{~cm}$ in West African Dwarf goat [26]; $2.0 \pm 0.3 \mathrm{~cm}$ in red Sokoto (Maradi) goats [25]; $2.45 \pm 0.00 \mathrm{~cm}$ in blackbuck [8]; $9.22 \pm 0.05 \mathrm{~cm}$ in dromedary camel [5] and $3.57 \pm 0.04 \mathrm{~cm}$ in local pig of Mizoram [6]. The mental nerve block can be achieved extraorally by injecting anaesthetic drugs approximately $2.8 \mathrm{~cm}$ in barking deer and $3 \mathrm{~cm}$ in of sambar deer from the lateral extent of the alveolar root of inferior third incisor tooth into the mental foramen. The mental nerve block is useful for desensitizing the lower lip during its surgical interventions.

The distance from the mental foramen to caudal border of the ramus of the mandible was $12.87 \pm$ $\pm 0.01 \mathrm{~cm}$ in males, $14.46 \pm 0.02 \mathrm{~cm}$ in females of barking deer and $23.66 \pm 0.01 \mathrm{~cm}$ in males, $23.59 \pm$ $\pm 0.01 \mathrm{~cm}$ in females of sambar deer, while the same parameters were $13.43 \pm 0.08 \mathrm{~cm}$ in blackbuck [8]; $11.69 \pm 0.40 \mathrm{~cm}$ in black Bengal goat [34]; $13.74 \pm$ $\pm 0.18 \mathrm{~cm}$ in Mehraban sheep [16]; $9.26 \pm 0.49 \mathrm{~cm}$ in Gwembe Valley Dwarf goat [17]; $32.12 \pm 0.16$ in dromedary camel [5]; $15.23 \pm 1.46 \mathrm{~cm}$ in Barbados black belly sheep [22]; $11.8 \pm 0.89 \mathrm{~cm}$ in black Bengal goat [29], $12.38 \pm 1.52 \mathrm{~cm}$ in Abaza goats [11] and $18.47 \pm 0.01 \mathrm{~cm}$ in local pig of Mizoram [6].

The length and height of the mandible was $15.77 \pm 0.01 \mathrm{~cm}, 7.88 \pm 0.01 \mathrm{~cm}$ in males and $17.27 \pm$ $\pm 0.02 \mathrm{~cm}, 7.78 \pm 0.02 \mathrm{~cm}$ in females of barking deer; and $28.10 \pm 0.01,15.96 \pm 0.01 \mathrm{~cm}$ in males and $27.96 \pm 0.01 \mathrm{~cm}, 15.78 \pm 0.02 \mathrm{~cm}$ in females of sambar deer, respectively. The same mandibular parameters were $12.00 \pm 0.89 \mathrm{~cm}, 6.90 \pm 1.09 \mathrm{~cm}$ for West African Dwarf goats [26]; $11.24 \pm 0.52 \mathrm{~cm}, 6.64 \pm 0.44 \mathrm{~cm}$ in Gwembe Valley Dwarf goat [17]; $16.53 \pm 0.12 \mathrm{~cm}$, $10.69 \pm 0.02 \mathrm{~cm}$ in blackbuck [7]; $42.98 \pm 0.62 \mathrm{~cm}$, $22.58 \pm 0.28 \mathrm{~cm}$ in dromedary camel [5] and $25.02 \pm$ $\pm 0.09,10.54 \pm 0.07 \mathrm{~cm}$ in local pig of Mizoram [6].

The distance between the condylar process to the height of the mandible, condylar process to the ventral margin of the mandible was $2.89 \pm 0.01 \mathrm{~cm}$, $4.89 \pm 0.01 \mathrm{~cm}$ in males and $2.79 \pm 0.01 \mathrm{~cm}, 4.39 \pm$ $\pm 0.01 \mathrm{~cm}$ in females of barking deer; and $5.29 \pm$ $\pm 0.01 \mathrm{~cm}, 10.60 \pm 0.01 \mathrm{~cm}$ in males and $5.21 \pm$ $\pm 0.01 \mathrm{~cm}, 10.50 \pm 0.01 \mathrm{~cm}$ in females of sambar deer. However, the same parameter has been reported to be $3.09 \pm 0.00 \mathrm{~cm}, 7.57 \pm 0.02 \mathrm{~cm}$ in blackbuck [7].

The distance between the vertical line drawn downward from the caudal border of the mandible (I) and the vertical line drawn from the mandibular foramen downwards (F) was (G) $2.15 \pm 0.01 \mathrm{~cm}$ in males, $2.09 \pm 0.01 \mathrm{~cm}$ in females of barking deer and $3.80 \pm 0.01 \mathrm{~cm}$ in males, $3.71 \pm 0.01 \mathrm{~cm}$ in females of sambar deer (Fig. 3). However, the same parameter was observed as $1.85 \pm 0.01 \mathrm{~cm}$ in blackbuck [7].

The mandibular nerve block is used to anesthetise the mandibular nerve during the clinical examinations and surgical procedures involving the alveoli and teeth of the lower jaw in animals [19]. The distances from the mandibular foramen to the ventral margin of the mandible, caudal border of mandible to the 
level of mandibular foramen, mandibular foramen to the border of mandibular angle were $2.49 \pm 0.01 \mathrm{~cm}$, $2.15 \pm 0.01 \mathrm{~cm}, 2.49 \pm 0.03 \mathrm{~cm}$ in males; $2.39 \pm$ $\pm 0.02 \mathrm{~cm}, 2.09 \pm 0.01 \mathrm{~cm}, 2.39 \pm 0.02 \mathrm{~cm}$ in females of barking deer and $5.17 \pm 0.01 \mathrm{~cm}, 3.80 \pm 0.01 \mathrm{~cm}$, $5.16 \pm 0.02 \mathrm{~cm}$ in males; $5.10 \pm 0.02 \mathrm{~cm}, 3.71 \pm 0.0 \mathrm{~cm}$, $5.11 \pm 0.01 \mathrm{~cm}$ in females of sambar deer (Fig. 3). Whereas, the same parameters were recorded as $4.18 \pm 0.01 \mathrm{~cm}, 1.36 \pm 0.01 \mathrm{~cm}, 3.07 \pm 0.00 \mathrm{~cm}$ in blackbuck [8]; $8.84 \pm 0.08 \mathrm{~cm}, 5.88 \pm 0.05 \mathrm{~cm}$, $8.29 \pm 0.07 \mathrm{~cm}$ in dromedary camel [5] and $4.56 \pm$ $\pm 0.01 \mathrm{~cm}, 3.81 \pm 0.00 \mathrm{~cm}, 4.84 \pm 0.00 \mathrm{~cm}$ in local pig of Mizoram [6]. Equivalent figures for West African dwarf goats of Nigeria were $1.57 \pm 0.44 \mathrm{~cm}$, $2.58 \pm 0.34 \mathrm{~cm}$ for the caudal border of the mandible to below mandibular foramen and the mandibular foramen to the ventral margin of the mandible [26]. In horse and dogs, the distance between the mandibular foramen and the ventral margin of the mandible was $3 \mathrm{~cm}$ and 1.5 to $2 \mathrm{~cm}$, respectively [15]. The mandibular nerve is useful during the treatment of the injuries related to the lower incisors and premolar tooth, i.e. dental extraction, tumours etc. An extraoral mandibular nerve block can be achieved by injecting anaesthetic drugs approximately $2.5 \mathrm{~cm}$ in barking deer and $5.0 \mathrm{~cm}$ in sambar deer from the horizontal plane at the level of the ventral margin of the mandible to the ventral limit of the mandibular foramen.

\section{CONCLUSIONS}

It is concluded that the measurements obtained from the present study will be useful for the surgeons to locate the site for infiltration of the anaesthetic drugs for the nerves of maxillofacial and mandibular regions and can aid the veterinary practitioners in treating the head injuries related to both the species. Further, it will be very useful in the future endeavours involving applied research works leading towards the massive improvement in the livestock sector of the international economy as well as conservation of wildlife.

\section{Acknowledgements}

The authors are thankful to the Dean, College of Veterinary Sciences and Animal Husbandry, Central Agricultural University (I), Aizawl, Mizoram; Principal Chief Conservator of Forest and Chief Wildlife Warden (PCCF and CWW), Government of Mizoram, Aizawl and Director, Aizawl Zoological Park, Aizawl, Mizoram for providing all the necessary facilities to carry out the research work.

\section{REFERENCES}

1. Adnyane IKM, Zuki ABZ, Noordin MM, et al. Morphological study of the infraorbital gland of the male barking deer, muntiacus muntjak. Afr J Biotech. 2011; 10(77), doi: 10.5897/ajb10.2634.

2. Barrette $C$. Musculature of facial scent glands in the muntjac. J Anat. 1976; 122(Pt 1): 61-66, indexed in Pubmed: 977477.

3. Barrette C. Social behavior of muntjac. Ph.D. Thesis submitted to the University of Calgary, Calgary, Alberta, Canada. 1975.

4. Choudhary O, Kalita P, Doley P, et al. Applied anatomy of the head region of the indian wild pig (sus scrofa) and its clinical value during regional anesthesia. J Anim Res. 2017; 7(2): 339, doi: 10.5958/2277-940x.2017.00049.3.

5. Choudhary OP, Kalita PC, Kalita A, et al. Applied anatomy of the maxillofacial and mandibular regions of the dromedary camel (Camelus dromedarius). J Camel Prac Res. 2016; 23(1): 127, doi: 10.5958/2277-8934.2016.00021.7.

6. Choudhary O, Kalita P, Konwar B, et al. Morphological and Applied Anatomical Studies on the Head Region of Local Mizo Pig (Zovawk) of Mizoram. Int J Morphol. 2019; 37(1): 196-204, doi: 10.4067/s0717-95022019000100196.

7. Choudhary O, Singh I, Bharti S, et al. Gross and Morphometrical Studies on Mandible of Blackbuck (Antelope cervicapra). Int J Morphol. 2015; 33(2): 428-432, doi: 10.4067/s0717-95022015000200003.

8. Choudhary O, Singh I. Applied Anatomy of the Maxillofacial and Mandibular Regions of the Indian Blackbuck (Antilope cervicapra). J Anim Res. 2015; 5(3): 497, doi: 10.5958/2277-940x.2015.00085.6.

9. Choudhary O, Singh I. Morphological and Radiographic Studies on the Skull of Indian Blackbuck (Antilope cervicapra). Int J Morphol. 2016; 34(2): 775-783, doi: 10.4067/ s0717-95022016000200055.

10. Choudhary O, Singh I. Morphometrical Studies on the Skull of Indian Blackbuck (Antelope cervicapra). Int J Morphol. 2015; 33(3): 868-876, doi: 10.4067/s071795022015000300011.

11. Dalga S. Topographic and morphometric study of the mental foramina of Abaza goats with its clinical implication for regional anesthesia. Folia Morphol. 2019 [Epub ahead of print], doi: 10.5603/FM.a2019.0122, indexed in Pubmed: 31750539.

12. Dyce KM, Sack WO, Wensing CJG. Textbook of Veterinary Anatomy. 2nd edn. Elsevier, Philadelphia 1996.

13. Getty R. Sisson and Grossman's The Anatomy of the Domestic Animals, 2nd edn. Vol. I. W.B. Saunders Co., Philadelphia 1975.

14. Ghosh RK. Primary Veterinary Anatomy, 5th edn. Current books international, Kolkata, West Bengal, India 2012.

15. Hall LW, Clarke KW, Trim CM. Wright's Veterinary Anesthesia. 10th edn. ELBS and Baillierre Tindall, London 2000.

16. Karimi I, Onar V, Pazvant G, et al. The cranial morphometric and morphologic characteristics of Mehraban sheep in western Iran. Global Vet. 2011; 6(2): 111-117.

17. Kataba A, Mwaanga ES, Simukoko $H$, et al. Clinical anatomy of the head Region of Gwembe Valley dwarf goat in Zambia. Int J Vet Sci. 2014; 3(3): 142-146.

18. Kumawat $R$, Joshi $S$, Mathur $R$, et al. Gross morphological studies on mandible of Indian spotted deer (Axis axis). Indian Vet J. 2014; 91(9): 105-107. 
19. Lahunta ADE, Habel RE. Applied veterinary anatomy. W.B. Saunders Co., Philadelphia 1986.

20. Leslie D. Rusa unicolor (Artiodactyla: Cervidae). Mammalian Species. 2011; 43: 1-30, doi: 10.1644/871.1.

21. Long JL. Introduced mammals of the world: their history, distribution and influence. CSIRO Publishing, Collingwood Victoria, Australia 2003

22. Mohamed R, Drisco M, Mootoo N. Clinical anatomy of the skull of the Barbados black belly sheep in Trinidad. Int J Curr Res Med Sci. 2016; 2(8): 8-19.

23. Monfared AL. Gross anatomical measurements of the head region of the Iranian native cattle (Bos taurus) and their clinical value for regional anesthesia. Global Vet. 2013; 10(2): 219-222, doi: 10.5829/idosi. gv.2013.10.2.724.

24. Ohtaishi N, Gao Y. A review of the distribution of all species of deer (Tragulidae, Moschidae and Cervidae) in China. Mammal Review. 1990; 20(2-3): 125-144, doi: 10.1111/j.1365-2907.1990.tb00108.x.

25. Olopade JO, Onwuka SK. Osteometric studies of the red Sokoto (Maradi) goats (Capra hircus): Implication for regional anaesthesia of the head. Int J Morphol. 2007; 25(2): 407-410, doi: 10.4067/S071795022007000200027.

26. Olopade J, Onwuka S. Some Aspects of the Clinical Anatomy of the Mandibular and Maxillofacial Regions of the West African Dwarf Goat in Nigeria. Int J Morphol. 2005; 23(1), doi: 10.4067/s0717-95022005000100006.
27. Ommer PA, Harshan KR. Applied Anatomy of Domestic Animals, 1 st edn. Jaypee brother's medical publisher, New Delhi, India 1995.

28. Onar V, Ozcan S, Pazvant G. Skull typology of adult male Kangal dogs. Anat Histol Embryol. 2001; 30(1): 41-48, doi: 10.1046/j.1439-0264.2001.00292.x, indexed in Pubmed: 11284162.

29. Poddar S, Faruq AA, Dey T, et al. Topographic and morphometr ic anatomy of mental foramen of black Bengal goat (Capra hircus) in Bangladesh with its clinical implication for regional anesthesia. Int J Zoo Anim Biol. 2018; 1(1), doi: 10.23880/izab-16000102.

30. Snedecor GW, Cochran WG. Statistical Methods. 8th edn. lowa State University Press, Ames, lowa, USA 1994.

31. Sundaram V, Dharani P, Gnanadevi R, et al. Studies on clinical anatomy of the maxillofacial and mandibular regions of the Madras Red sheep (Ovis aries) in India. Folia Morphol. 2019; 78(2): 389-393, doi: 10.5603/FM.a2018.0098, indexed in Pubmed: 30371934.

32. Timmins RJ, Duckworth JW, Hedges S. Muntiacus muntjak. The IUCN Red List of Threatened Species. International Union for Conservation of Nature and Natural Resources, IUCN 2016.

33. Timmins RJ, Kawanishi K, Giman B, et al. Rusa unicolor. The red list of threatened species. IUCN 2015.

34. Uddin $\mathrm{M}$, Ahmed $\mathrm{S}$, Islam $\mathrm{K}$, et al. Clinical anatomy of the head region of the black bengal goat in bangladesh. Int J Morphol. 2009; 27(4), doi: 10.4067/s071795022009000400048. 